\title{
Defective IL-10 production in severe phenotypes of Crohn's disease
}

\author{
Ismael Correa, ${ }^{*}$ Marisol Veny, ${ }^{\dagger}$ Miriam Esteller, ${ }^{\dagger}$ Josep $\mathrm{M}^{a}$ Piqué,${ }^{\star}$ Jordi Yagüe, ${ }^{\ddagger}$ Julián Panés, ${ }^{\star}$ \\ and Azucena Salas ${ }^{\dagger, 1}$ \\ Departments of $*^{*}$ Gastroenterology and ${ }^{\ddagger}$ Immunology, Hospital Clínic, IDIBAPS, and ${ }^{\dagger}$ Department of Ischemia and \\ Inflammation, Institut d'Investigaciones Biomèdiques de Barcelona (IIBB)-Consejo Superior de Investigaciones \\ Científicas, CIBER-EHD, Barcelona, Spain
}

\begin{abstract}
Loss of tolerance toward commensal bacteria has been invoked as a mechanism for Crohn's disease. IL-10 is a key anti-inflammatory cytokine that plays a role in induction and maintenance of tolerance. The aim of this study is to determine IL-10 production in response to bacterial components in Crohn's disease patients, who were classified according to their phenotypes as stricturing, penetrating, or inflammatory. Peripheral blood was obtained from Crohn's disease patients and healthy controls. Cytokine production was measured in whole blood cultures, isolated $\mathrm{CD4}^{+}$cells, and monocyte-derived dendritic cells (MDDCs). Under unstimulated conditions, IL-10, but not IL-12, was down-regulated significantly in blood cultures of patients with severe phenotypes, compared with inflammatory, nonpenetrating, nonstricturing Crohn's disease patients. In response to LPS, IL-10 was up-regulated more significantly in patients with no fistulae or fibrosis. Study of IL-10 production by isolated cell subsets showed that DCs, but not $\mathrm{CD4}^{+} \mathrm{T}$ cells, from penetrating Crohn's disease produced significantly less IL-10 in response to LPS. Differences were not associated with the $1082 \mathrm{~A} / \mathrm{G}$ polymorphism in the IL-10 gene promoter. We show a defect in IL-10 production in whole blood cell cultures and MDDCs in patients with severe forms of Crohn's disease. This defect in IL-10 production by a group of Crohn's disease patients may represent a mechanism mediating more severe manifestations of the disease. We propose that treatment with IL-10 or IL-10-inducing therapies could be of particular benefit to these group of patients. J. Leukoc. Biol. 85: 000-000; 2009.
\end{abstract}

Key Words: dendritic cell $\cdot I L-12$

\section{INTRODUCTION}

Crohn's disease is a chronic relapsing, inflammatory disease characterized by patchy transmural inflammation that can involve any part of the intestinal tract. Whereas the location of the disease appears to remain fairly constant over time for each individual, other clinical features, such as the presence of intra-abdominal or perianal fistulae, as well as the development of intestinal fibrosis, can change significantly over time [1]. This wide variability over the course of the disease makes classification of patients with Crohn's disease complex and suggests multiple factors are involved in its development.

The working party for an integrated classification of inflammatory bowel disease (IBD) has designated three main phenotypes for Crohn's disease: stricturing (stenosing), penetrating (fistulizing), and nonpenetrating, nonstricturing (also termed inflammatory). Although the clinical criteria for patient classification have been established, little is known about the underlying molecular mechanisms that lead to segregation of patients suffering from Crohn's disease into the different groups. In other words, the molecular events leading to the formation of stenosis in some cases and/or fistula in others remain largely unknown, limiting the development of specific therapies for these conditions.

However, it is well accepted that manifestation of the disease requires the interaction of the intestinal flora with the gut mucosal immune system in a genetically predisposed individual [2]. This interaction is orchestrated by several cell types of the innate immune system that mediate the events from early immune responses to polarization and activation of effector $\mathrm{T}$ cells. To accomplish this, monocytes, macrophages, dendritic cells (DCs), and epithelial cells are equipped with patternrecognition receptors (PRRs) that allow them to sample conserved bacterial molecular patterns. These receptors include TLRs, as well as members of the nucleotide-binding oligomerization domain (NOD)-leucine-rich-repeat protein family, such as NOD2 [3]. Innate immune responses are important in the initial fight against bacteria, and a constitutive defect in Crohn's disease patients in mounting this type of immune response has been reported previously [4]. Further, supporting the role of bacterial-mediated innate immune responses in Crohn's disease pathology, a loss of function polymorphism in the LPS receptor TLR4, Asp299Gly, has been associated with

\footnotetext{
${ }^{1}$ Correspondence: Department of Experimental Pathology, Institut d'Investigaciones Biomèdiques de Barcelona (IIBB)-CSIC, Rosselló 161, Barcelona 08036, Spain. E-mail: azsbam@iibb.csic.es

Received November 14, 2008; revised December 22, 2008; accepted January $8,2009$.

doi: $10.1189 / \mathrm{jlb} .1108698$
} 
a certain subgroup of Crohn's disease patients [5]. Moreover, loss of function mutation of the NOD2 gene, which is involved in muramyldipeptide (a peptidoglycan component) recognition, has been strongly associated not only with a higher risk of developing Crohn's disease [6, 7] but also with early-on surgical intervention as a result of stenosis and surgical recurrence [8].

IL-10 is an anti-inflammatory cytokine that is produced by cellular components of the innate immune system in response to PRR ligation. IL-10 can inhibit Thl effector responses and skew the polarization of naïve $\mathrm{T}$ cells toward a regulatory phenotype [9]. The therapeutic potential of recombinant human (rh)IL-10 administration has been assessed previously in Crohn's disease, although the benefits are limited [10, 11].

Given the importance of IL-10-mediated immune responses in maintaining intestinal homeostasis and tolerance toward commensal flora, we hypothesized that a defect in IL-10 production may be involved in the pathogenesis of Crohn's disease and in particular, in the development of the more severe manifestations of the disease, such as fistulae or stenosis. Together, our results show a systemic defect in the ability of patients suffering severe forms of Crohn's disease to up-regulate IL-10 production in response to bacterial products. DCs are particularly impaired in their ability to produce IL-10 in penetrating phenotypes. We speculate that this defect may have a negative influence on the generation of IL-10-producing regulatory T cells (Tregs). Based on our results, we propose that patients possessing a penetrating phenotype could benefit most from treatment with rhIL-10.

\section{MATERIALS AND METHODS}

\section{Subjects}

Peripheral blood was obtained from Crohn's disease patients with quiescent disease and healthy controls. None of the subjects had suffered from any infectious diseases or hospitalizations in the previous month, and none presented any of the common (see below) NOD2/caspase recruitment domain family, member 15 (CARD15), gene polymorphisms. Diagnosis of Crohn's disease had been established at least 5 years prior, based on clinical, radiological, endoscopic, and histological criteria reported previously [12]. At the outset of the study, all patients were in clinical remission, as defined by a Crohn's disease activity index $(\mathrm{CDAI})<150$ and C-reactive protein $<8 \mathrm{mg} / \mathrm{L}$. Disease behavior was established according to the Montreal classification: penetrating for intra-abdominal fistulas, inflammatory masses, and/or abscess; stricturing for patients who needed surgery involving bowel resection; and inflammatory for those patients lacking either of the two previous phenotypes [13]. All patients gave their written, informed consent following approval of the project by the Hospital Clinic Ethics Committee (Barcelona, Spain). The study was performed in accordance with the principles set forth in the Declaration of Helsinki.

\section{Blood cultures and cell separation}

Peripheral blood from healthy controls or Crohn's disease patients was harvested in heparinized tubes and diluted (1:3) in complete medium (CM): RPMI supplemented with $50 \mu \mathrm{g} / \mathrm{ml}$ gentamicin (Braun, Germany) and $100 \mathrm{U} / \mathrm{ml}$ penicillin, $100 \mathrm{U} / \mathrm{ml}$ streptomycin, and $250 \mathrm{ng} / \mathrm{ml}$ amphotericin B (BioWhittaker, Lonza, Gaithersburg, MD, USA). Diluted blood $(600 \mu \mathrm{l})$ was incubated in 24-well plates for $18 \mathrm{~h}$, with or without $10 \mathrm{ng} / \mathrm{ml}$ LPS or $20 \mu \mathrm{g} / \mathrm{ml}$ palmitoyl-3-cysteine-serine-lysine-4 ( $\mathrm{Pam}_{3} \mathrm{CSK} 4$; InvivoGen, San Diego, CA, USA). Blood was centrifuged, and supernatants were frozen at $-80^{\circ} \mathrm{C}$ for later analysis.
To obtain CD4 ${ }^{+}$T cells, PBMC were isolated by standard Ficoll gradient. Cells were plated in T75 flasks, and adherent cells were discarded. $\mathrm{CD} 4^{+}$cells were isolated by positive selection using magnetic beads (Miltenyi Biotec, Germany) and plated $\left(5 \times 10^{5}\right.$ cells/well) on $1 \mu \mathrm{g} / \mathrm{ml}$ aCD3-precoated 48-well plates in the presence of $1 \mu \mathrm{g} / \mathrm{ml}$ aCD28 or for unstimulated conditions, in the presence of the isotype-matched Igs. Cultures were carried out in CM containing $100 \mathrm{U} / \mathrm{ml} \mathrm{IL}-2$. Supernatants were harvested after a 6-day culture and frozen at $-80^{\circ} \mathrm{C}$ for later cytokine concentration measurement.

\section{ELISA}

Sandwich ELISA was used to determine cytokine (IL-10 and total IL-12) production by whole blood or $\mathrm{CD} 4^{+}$activated T cells. Capture and biotinylated $\mathrm{mAb}$ were obtained from eBioscence (San Diego, CA, USA) or Mabtech (Sweden), and purified recombinant cytokines used as standards for quantification were acquired from Peprotech (Rocky Hill, NJ, USA).

\section{Antibodies for flow cytometric assay}

We used the following antibodies all from Becton Dickinson (San Diego, CA, USA): CD3-FITC, CD14-FITC, CD19-FITC, CD56-FITC, CD40-FITC, CD80FITC, CD83-FITC, CD86-FITC, CD11c-PE, and HLA-DR-PerCP. Isotypematched controls were obtained from the same manufacturer.

\section{Generation of monocyte-derived DCs (MDDCs) and isolation of lymphocytes for allogeneic cocultures}

Immature DCs were generated in vitro from circulating monocytes by culturing them with IL-4 and GM-CSF [14]. Briefly, human PBMC were isolated from 70 $\mathrm{ml}$ heparinized blood via a standard Ficoll gradient. For monocyte enrichment, $20-40 \times 10^{6} \mathrm{PBMC}$ were cultured in $6 \mathrm{ml} \mathrm{CM}$ for $2 \mathrm{~h}$ at $37^{\circ} \mathrm{C}$ in a humid atmosphere at $5 \% \mathrm{CO}_{2}$. Adherent cells were washed three times with prewarmed RPMI (Sigma-Aldrich, Spain) and then cultured with CM at $37^{\circ} \mathrm{C}$ in a humid atmosphere at $5 \% \mathrm{CO}_{2}$. Cells were differentiated for 7 days to obtain immature DCs by adding $1000 \mathrm{U} / \mathrm{ml} \mathrm{IL-4}$ and $1000 \mathrm{U} / \mathrm{ml} \mathrm{GM-CSF}$ (ProspecTany Technogene, Israel) on Days 0,2 , and 4. Lymphocytes were obtained from allogeneic buffy coats. Briefly, PBMC were isolated from buffy coats using a standard Ficoll gradient. $\mathrm{CD}^{+}{ }^{+}$lymphocytes were isolated as described above and resuspended in CM.

\section{ELISpot assays and allogeneic cocultures}

The number of IFN- $\gamma$-, IL-12 (p35/p40 heterodimer)-, IL-10-, and IL-13producing cells was determined by ELISpot (Mabtech) following the manufacturer's instructions. DCs, 15,000/well or 5000/well, for IL-10 and IL-12, respectively, were incubated for $36 \mathrm{~h}$ in ELISpot plates in duplicate in the presence of medium alone, $10 \mathrm{ng} / \mathrm{ml}$ ultra-pure Escherichia coli K12 LPS (InvivoGen), or $20 \mu \mathrm{g} / \mathrm{ml}$ bacterial synthetic lipopeptide Pam ${ }_{3}$ CSK 4 (InvivoGen).

For allogeneic cocultures, 5000/well DCs and 100,000/well CD4 ${ }^{+}$lymphocytes were seeded in precoated anti-IFN- $\gamma$ or anti-IL-13 ELISpot plates in duplicate. Following a $60-\mathrm{h}$ culture, the number of IFN- $\gamma$ - or IL-13-producing cells was determined following the manufacturer's instructions.

\section{NOD2/CARD15 and IL-10 genotyping}

Genomic DNA from whole blood samples was isolated using a QIAmp DNA blood mini kit (Qiagen, Germany), following the manufacturer's instructions. For NOD2/CARD15 genotyping, specific sequences of exon 4 (missense mutation R702W), exon 8 (missense mutation G908R), and exon 11 (frameshift mutation L1007finsC) from the NOD2/CARD15 gene were amplified by PCR, using specific primers published previously (primer 4-CF: GAAGTACATCCGCACCGAG, and primer 4-ER: GCTCCCCCATACCTGAAC; primer 11forward: CTCACCATTGTATCTTCTTTC, and primer 11-reverse: GAATGTCAGAATCAGAAGGG) [8]. The PCR products were purified using a QIAquick PCR purification kit (Qiagen), according to the manufacturer's instructions, sequenced using an ABI Bigdye terminator vl.1 cycle sequencing kit (Applied Biosystems, Foster City, CA, USA), and run on an ABI 3100 automatic sequencer.

We genotyped the IL-10 promoter region via PCR amplification using a Taq DNA polymerase Expand ${ }^{\mathrm{TM}}$ high-fidelity PCR system (Boehringer Mannheim 
TABLE 1. Characteristics of the Study Population

\begin{tabular}{|c|c|c|c|c|c|c|}
\hline Controls & 12 & $30 \pm 5.3$ & 5 vs. 7 & n.a. & n.a. & n.a. \\
\hline Stricturing & 17 & $45 \pm 12$ & 14 vs. 3 & $12.2 \pm 7.0$ & $6 / 1 / 12 / 0$ & 5 vs. 12 \\
\hline Penetrating & 15 & $39 \pm 9$ & 12 vs. 3 & $9.0 \pm 2.9$ & $2 / 1 / 12 / 0$ & 0 vs. 15 \\
\hline
\end{tabular}

Healthy controls and Crohn's disease patients with a duration of disease of more than 5 years were included. ${ }^{a}$ Medication groups, No medication/steroids/ immunosuppressors/anti-TNF. n.a., not applicable.

GmbH, Germany) [15]. Primers that amplified the segment of the IL-10 gene promoter from -1120 to -533 were used (IL10.1, 5'-ATCCAAGACAACACTACTAA-3' , and IL10.2, 5' ${ }^{\prime}$ TAAATATCCTCAAAGTTCC- $3^{\prime}$ ). PCR products were sequenced with an $\mathrm{ABI}$ Prism ${ }^{\mathrm{TM}}$ dRhodamine terminator cycle sequencing ready reaction kit, following the manufacturer's instructions and with 2.5 pmol upstream IL10.1 primer. Samples were then run on an ABI Prism 377 system.

\section{Statistical analysis}

Statistical analysis was carried out with Statview, Version 5.0. Data are expressed as the mean $\pm \mathrm{SE}$. Differences among multiple groups were assessed by ANOVA with Bonferroni as a post-hoc correction for multiple comparisons. A Mann-Whitney test was performed when only two experimental groups existed. When appropriate, a paired Student's $t$-test was used. Values of $P<$ 0.05 were considered significant.

\section{RESULTS}

\section{IL-10 production in whole blood samples differs among Crohn's disease phenotypes}

To detect constitutive alterations in inflammatory/anti-inflammatory responses in Crohn's disease patients and particularly between groups of individuals with different disease phenotypes, we measured cytokine production in whole blood cell cultures from healthy controls and Crohn's disease patients with quiescent disease states (Table 1). We use whole blood cell cultures and show our results as pg cytokine/ml blood to try to mimic ex vivo the conditions present in the periphery. The number of total blood cells (lymphocytes, monocytes, and granulocytes) was determined in all samples and did not vary significantly among groups (Table 2).

As shown in Figure 1, unstimulated blood cells produced similarly low amounts of IL-12 in all groups studied. In contrast, a comparison between groups of Crohn's disease patients revealed differences in IL-10 production by unstimulated

TABLE 2. Total Number of Leukocytes in Peripheral Blood Samples

\begin{tabular}{lrcr}
\hline \hline & $\begin{array}{c}\text { Lymphocytes } \\
\left(\times 10^{3} / \mathrm{ml}\right)\end{array}$ & $\begin{array}{c}\text { Monocytes } \\
\left(\times 10^{3} / \mathrm{ml}\right)\end{array}$ & $\begin{array}{c}\text { Neutrophils } \\
\left(\times 10^{3} / \mathrm{ml}\right)\end{array}$ \\
\hline Healthy controls & $2.12 \pm 0.24$ & $0.32 \pm 0.027$ & $4.61 \pm 0.71$ \\
Inflammatory CD & $1.8 \pm 0.17$ & $0.37 \pm 0.048$ & $5.24 \pm 0.55$ \\
Stricturing CD & $1.45 \pm 0.38$ & $0.32 \pm 0.033$ & $3.98 \pm 0.54$ \\
Penetrating CD & $1.34 \pm 0.27$ & $0.38 \pm 0.035$ & $4.31 \pm 0.32$
\end{tabular}

Routine analytical cell count was performed from peripheral blood samples drawn from healthy and Crohn's disease (CD) patients. whole blood cell cultures, and stricturing and penetrating Crohn's disease patients produced significantly lower amounts of IL-10 than patients with a purely inflammatory phenotype.

Whole blood cell cultures were also stimulated with the bacterial-derived products LPS or $\mathrm{Pam}_{3} \mathrm{CSK} 4$, which bind to the PRRs TLR-4 and TLR-2, respectively. Stimulation of whole blood cells with either TLR ligand induced a significant increase in IL-10 as well as IL-12 production in all groups studied (Fig. 1). Interestingly, cultures from patients manifesting less-severe forms of the disease (purely inflammatory phenotype) produced the largest amounts of IL-10 in response to LPS or Pam 3 CSK4 stimulation compared with all of the other groups studied. As seen in Table 1, there was a predominance of male individuals in the stricturing and penetrating groups, which also show the lowest production of IL-10. To rule out the possibility that the differences observed were a result of gender rather than a phenotype-specific factor, we compared IL-10 production by whole blood cell cultures between male and female patients (in the inflammatory group and the healthy control groups) and detected no significant differences in IL-10 production between males and females (Mann-Whitney test, $P=0.4822$ ).

In these same groups, however, IL-12 production in response to TLR stimulation was comparable in healthy controls and the various phenotypic subgroups of Crohn's disease patients.

\section{Lower systemic IL-10 concentrations in stricturing and penetrating Crohn's disease patients are not explained by a polymorphism in the IL-10 promoter}

Several described polymorphisms in the IL-10 gene promoter influence IL-10 synthesis. Here, we examined the presence of the polymorphism $1082 \mathrm{~A} / \mathrm{G}$, which has been associated with lower leukocyte production of IL-10 production [15, 16]. Table 3 shows the distribution of the different alleles among the patient groups. A $\chi^{2}$ test revealed a significant association between the stricturing phenotype and the AG genotype. However, although patients with the AA genotype had numerically lower values of basal and stimulated IL-10 production, differences were not statistically significant $(P>0.05$ using an ANOVA test with Bonferroni as a post-hoc correction for multiple groups). Therefore, at least in our series of patients, no association was seen between the IL-10 gene promoter 1082A/G genetic variant and basal or LPS-stimulated IL-10 production (Table 4). 
Fig. 1. Cytokine production in whole blood cell cultures unstimulated or stimulated with LPS or synthetic lipopeptide $\mathrm{Pam}_{3}$ CSK4. Whole blood was diluted in CM and cultured for $18 \mathrm{~h}$. Diluted plasma was separated and IL-10 or IL-12 concentration measured by sandwich ELISA. Values represent mean $\pm \mathrm{sE} ;+, P<0.05$, versus control; *, $P<0.05$, versus the corresponding stimulus in the inflammatory group.

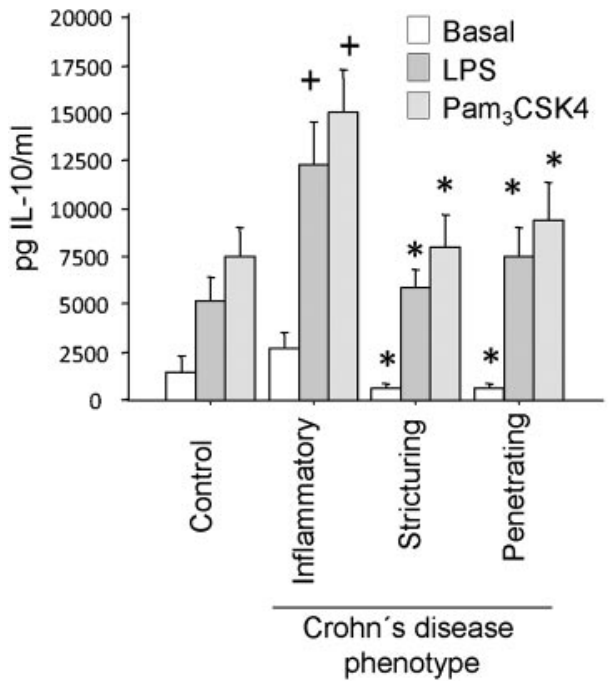

\section{IL-10 production by activated peripheral $\mathrm{CD} 4^{+} \mathrm{T}$ cells is not altered in severe phenotypes of Crohn's disease}

As IL-10 can be produced by a wide variety of cell types of myeloid or lymphoid descent, we tested whether this defect in IL-10 production was universal or restricted to certain cell types.

We first determined IL-10 production by resting and activated $\mathrm{CD}_{4}^{+}$lymphocytes isolated from peripheral blood of healthy controls and patients with quiescent Crohn's disease. IL-10 production by $\mathrm{CD}_{4}^{+}$cells in response to activation with anti-CD3/anti-CD28 mAb increased significantly in all groups. We observed no significant differences between $\mathrm{CD}_{4}^{+}$cells from inflammatory, stricturing, or penetrating phenotypes among them or compared with healthy controls in their ability to produce IL-10 (Fig. 2, left) or IFN- $\gamma$ (Fig. 2, right).

\section{MDDCs in penetrating Crohn's disease produce low amounts of IL-10}

We next asked whether IL-10 production by innate immune system cells from patients with different disease phenotypes was compromised in response to bacterial components.

Immature MDDCs obtained from healthy individuals or patients with quiescent Crohn's disease were linage-negative (CD3, CD14, CD19, CD56) and HLA-DR- and CD11c-positive and presented low or no expression of costimulatory molecules

TABLE 3. Genetic Analysis of the IL-10 Promoter 1082A/G Polymophism

\begin{tabular}{lccc}
\hline \hline & \multicolumn{3}{c}{ Crohn's disease phenotype } \\
\cline { 2 - 4 } & Inflammatory & Stricturing & Penetrating \\
\hline AA & 5 & 0 & 3 \\
AG & 5 & 9 & 3 \\
GG & 4 & 0 & 2 \\
\hline
\end{tabular}

The number of Crohn's disease patients with the different phenotypes carrying the AA, AG, or GG alleles is shown.
(CD40, CD80, and CD86) or CD83 (a marker of maturation; data not shown). No differences were observed in the expression patterns of DC markers on cells differentiated from healthy individuals or Crohn's disease patients (data not shown).

To determine the ability of these cells to mount an innate immune response, we cultured immature MDDCs in the presence of medium alone, LPS, or Pam ${ }_{3} \mathrm{CSK} 4$. As could be seen in whole blood cell cultures, both TLR ligands induced IL-10 production. The number of IL-10 producing DCs in healthy individuals $(51.7 \pm 11.96$ basal, 493.9 \pm 99.9 LPS, and 150.7 $\pm 26.2 \mathrm{Pam}_{3} \mathrm{CSK} 4 \mathrm{IL}^{-10}{ }^{+}$cells; $P<0.01$ paired $t$-test basal vs. LPS or $\left.\mathrm{Pam}_{3} \mathrm{CSK} 4\right)$ as well as in the overall group of Crohn's disease patients (89.1 \pm 32.7 basal, 285.6 \pm 69.6 LPS, and $223.1 \pm 51.5 \mathrm{Pam}_{3} \mathrm{CSK} 4 ; P<0.01$ paired $t$-test basal vs. LPS or Pam ${ }_{3}$ CSK4) increased significantly in response to stimulation. However, when individuals with Crohn's disease were separated based on their clinical phenotype, a defect in IL-10 production by DCs in penetrating Crohn's disease was revealed. Patients classified as inflammatory or stricturing presented a number of IL-10-producing cells in response to LPS, comparable with that of healthy controls. In contrast, patients with a penetrating phenotype exhibited a decreased number of IL-10-producing DCs in response to LPS (Fig. 3A). Moreover, the number of IL-10-producing DCs from patients with pene-

TABLE 4. Production of IL-10 by Whole Blood Cell Cultures from Crohn's Disease Patients with Different Alleles for the IL-10 Gene Promoter Polymorphism

\begin{tabular}{lcr}
\hline \hline & \multicolumn{2}{c}{ IL-10 $(\mathrm{pg} / \mathrm{ml})$} \\
\cline { 2 - 3 } & Unstimulated & \multicolumn{1}{c}{ LPS } \\
\hline AA & $621 \pm 365$ & $6567 \pm 1708$ \\
AG & $1521 \pm 483$ & $9293 \pm 1696$ \\
GG & $2387 \pm 1398$ & $11,908 \pm 3029$ \\
\hline
\end{tabular}

IL-10 production was measured in whole blood under unstimulated conditions or after $18 \mathrm{~h}$ LPS culture. Values represent mean concentration $\pm \mathrm{SE}$. 


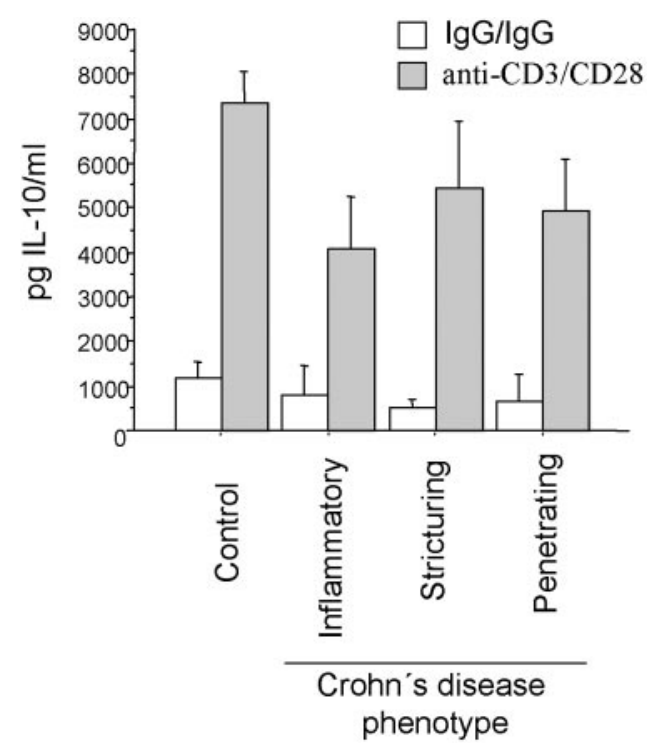

trating Crohn's disease was also significantly lower than that of purely inflammatory ones. That was true in response to LPS and $\mathrm{Pam}_{3} \mathrm{CSK} 4$.

In comparison with whole blood cell cultures, DCs from patients with an inflammatory phenotype responded to LPS similarly to healthy individuals. Certain discrepancies can be expected between cytokine production in whole blood versus isolated cell cultures. Whole blood cultures contain myriad cell populations and soluble factors that can interact with each other and affect cytokine production. The fact that exacerbated IL-10 production in the inflammatory phenotype was only observed in whole blood cultures could reflect precisely the contribution of these interactions unique to that environment. This is certainly an interesting possibility but cannot be answered by our results alone. From the current results, however, we can conclude that isolated DCs from patients with a pene- trating phenotype do show a defect in their ability to produce IL-10 in response to a relevant bacterial signal.

In keeping with what we observed in whole blood cell cultures, however, DCs showed no differences among groups in their ability to produce the proinflammatory cytokine IL-12 in response to TLR ligands LPS or Pam 3 CSK4 (Fig. 4, A and B).

We next asked whether the differences observed could affect the ability of these DCs to mount an allogeneic Thl (IFN- $\gamma$ ) or Th2 (IL-13) cell response. IL-13 production has also been suggested to be associated to fibrogenesis in intestinal inflammation $[17,18]$. We carried out allogeneic cocultures of immature MDDCs from all groups studied and $\mathrm{CD} 4^{+} \mathrm{T}$ cells from healthy donors. Following a $60-\mathrm{h}$ culture, the number of IFN- $\gamma$ and IL-13-producing cells was determined by ELISpot. As can be seen in Figure 5, DCs from all phenotypes induced similar numbers of IFN- $\gamma^{+}$or IL- $13^{+}$cells in allogeneic cocultures.
A

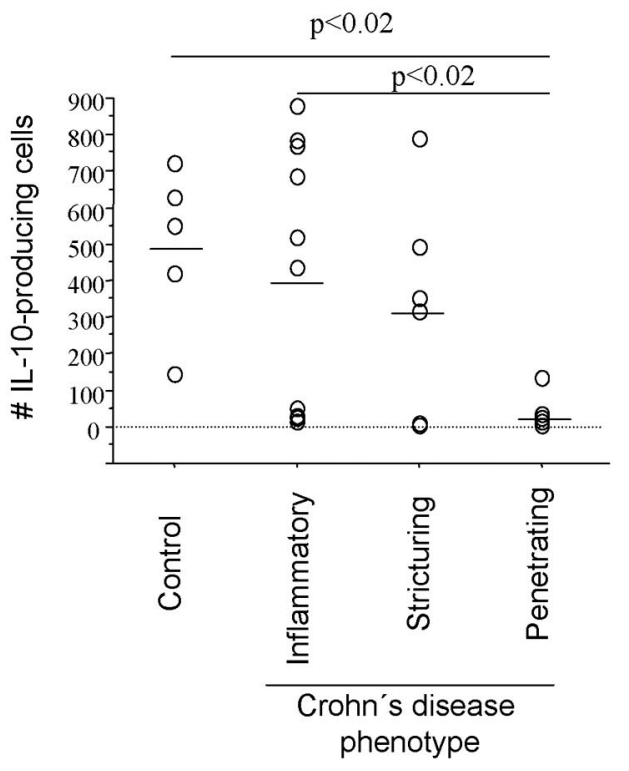

B

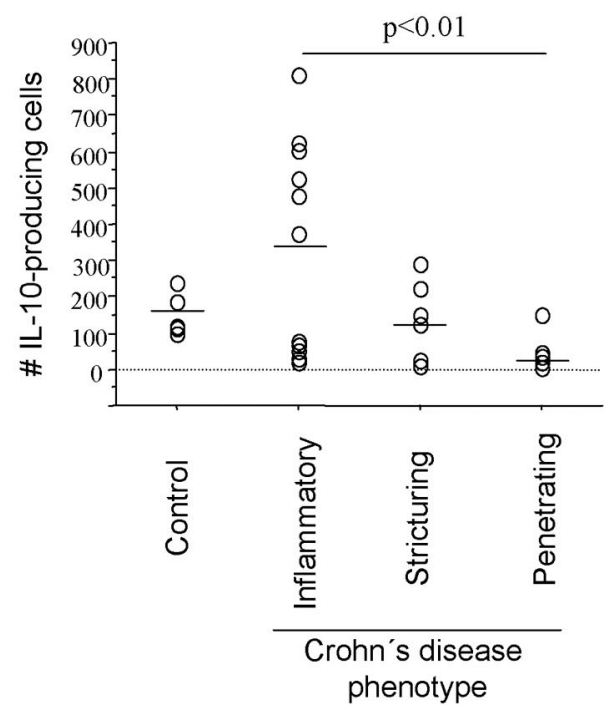

Fig. 3. Number of DCs producing IL-10 as determined by ELISpot. MDDCs from healthy controls or Crohn's disease patients were cultured in the presence of (A) LPS or (B) synthetic lipopeptide $\mathrm{Pam}_{3} \mathrm{CSK} 4$, and the number of IL-10-producing cells was measured by ELISpot. Horizontal lines represent mean values for each group. 
Fig. 4. Number of DCs producing IL-12 as determined by ELISpot. MDDCs from healthy controls or Crohn's disease patients were cultured in the presence of (A) LPS or (B) synthetic lipopeptide $\mathrm{Pam}_{3} \mathrm{CSK} 4$, and the number of IL-12-producing cells was measured by ELISpot. Horizontal lines represent mean values for each group.
A

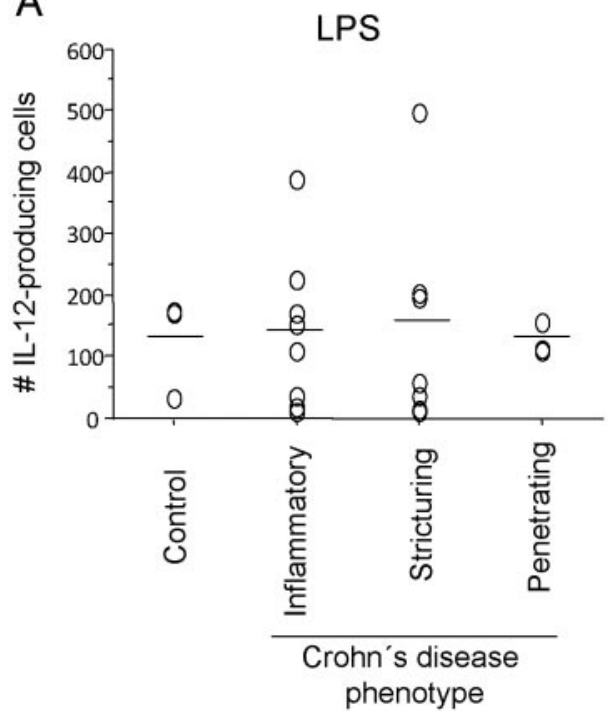

B

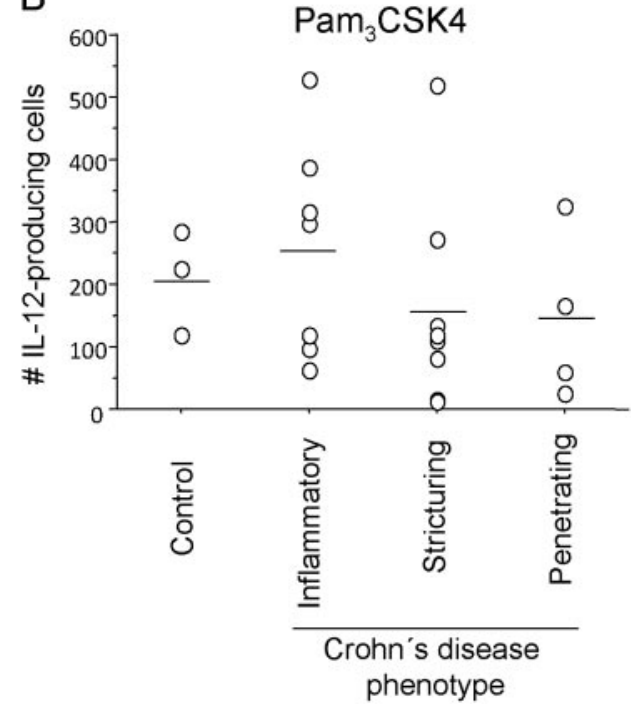

\section{DISCUSSION}

IL-10 is a pleiotropic cytokine produced by T cells, B cells, macrophages, DCs, monocytes, and mast cells. IL-10 exerts strong, immunomodulatory actions, including the inhibition of proinflammatory cytokine production (TNF- $\alpha$, IL-6, and IL-12) by myeloid cells, the suppression of Thl $\mathrm{T}$ cell polarization, and the induction and maintenance of oral tolerance $[9,19]$. IL-10 is also an essential growth factor for Tregl cells in vitro, which in turn, are important IL-10 producers [20].

A large body of evidence supports the role of IL-10 in maintaining the immune balance of intestinal mucosa. In particular, IL-10 gene disruption in mice results in the development of spontaneous enterocolitis that histologically resembles human Crohn's disease [21]. Interestingly, the development of colitis in IL-10-deficient mice is dependent on the presence of commensal bacteria [22] and signaling through the MyD88/ TLR. This suggests that IL-10 produced in response to TLRdependent bacterial stimulation is essential for maintaining mucosal tolerance to enteric flora [23]. IL-10-producing Tregs have been postulated to play a role in maintaining intestinal health, as the prevention of colitis by Tregs in an experimental model of colitis has been shown to be dependent on their ability to produce IL-10 [24].

In human Crohn's disease, the low production of IL-10 in intestinal mucosa is associated with increased postoperative recurrence [25, 26]. Moreover, administration of rIL-10 in low, but not high, producers of the cytokine reduced endoscopic recurrence significantly after surgery [26]. Systemic treatment of Crohn's disease patients with rhIL-10, however, has been attempted, but with only modest therapeutic benefit $[10,11]$. The lack of effect of IL-10 treatment has been attributed to limited mucosal bioavailability, and efforts have been made to explore alternative delivery protocols that would increase IL-10 concentration in the affected intestinal mucosa [27-29]. Interestingly, in clinical trials testing the therapeutic effects of rhIL-10 administration, a higher CDAI, which takes into account the presence of fistulae, correlated with an enhanced
Fig. 5. Number of cells producing IFN- $\gamma$ or IL-13 in allogeneic cocultures. MDDCs obtained from healthy controls or Crohn's disease patients were cocultured with allogeneic CD4+ cells. The number of (A) IFN- $\boldsymbol{\gamma}$ - or (B) IL-13-producing cells was determined by ELISpot. Horizontal lines represent mean values for each group.
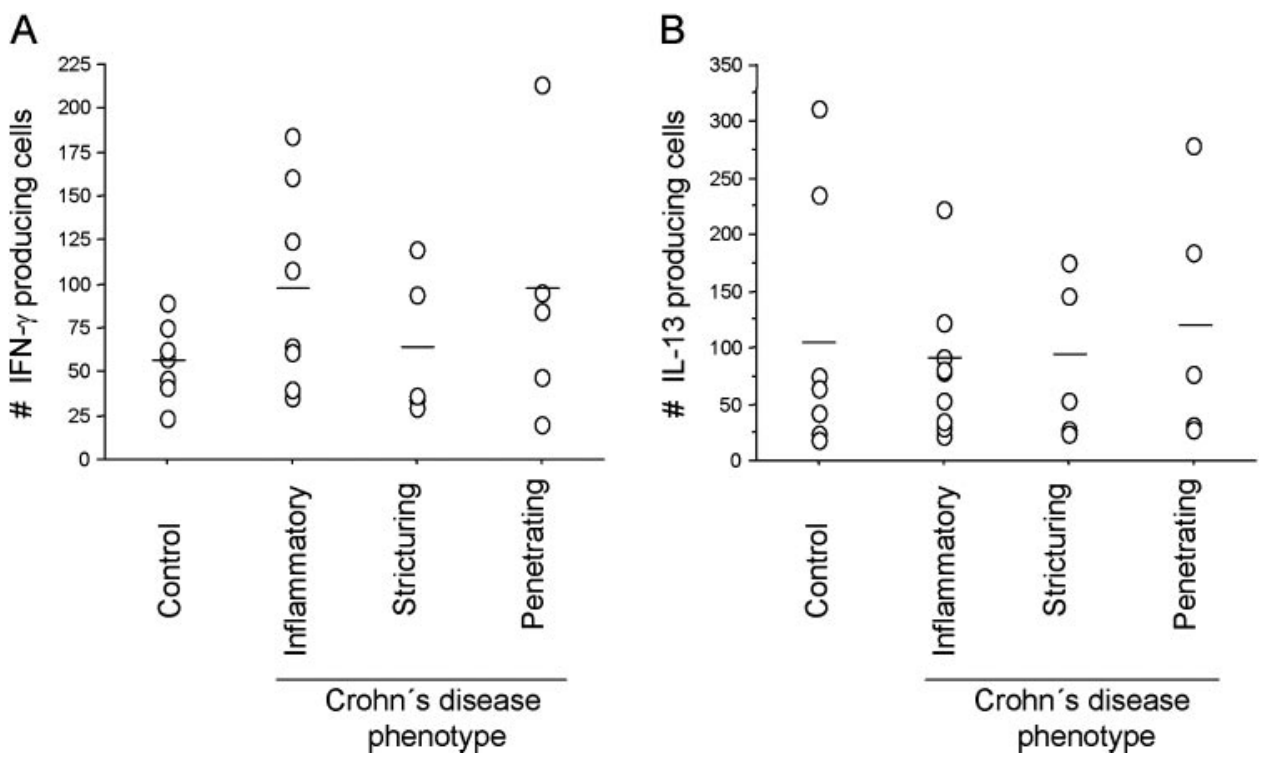
responsiveness to rhIL-10 treatment [11]. None of the clinical trials published thus far, however, separated patients based on their phenotypic characteristics nor did they compare their differential responses to IL-10 administration. Here, we show that IL-10 deficiency is more pronounced in patients with a penetrating phenotype, even during remission, which suggests that this group of patients may benefit greatly from rhIL-10 administration.

Previous studies have dealt with possible variations in IL-10 production by PBMC or lamina propria mononuclear cells from IBD patients. IL-10 secretion by lamina propria mononuclear cells from inflamed (Crohn's disease and ulcerative colitis) mucosa has been shown to be significantly lower than that of cells from noninflamed areas in response to PHA activation, whereas serum concentrations were not affected in either patient group compared with healthy controls [30]. Another study showed that active Crohn's disease is associated with higher circulating memory $\mathrm{CD}^{+}$lymphocytes, with low percentages of IL-10 producers in the $\beta 7^{-}$or in the mucosal homing $\beta 7^{+}$ memory pools [31]. Our results, therefore, are in agreement with previous evidence showing a defect in IL-10 production in Crohn's disease patients. In addition, we provide evidence that those patients presenting a more severe phenotype of the disease were the lower producers of IL-10. Important variability in IL-10 secretion by blood cells has been reported in humans and has been demonstrated to be associated with polymorphisms in the IL-10 gene promoter [15, 32]. Data from a previous report involving a low number of patients suggest an association between the IL-10 genotypes and IBD [16]. However, in our series of patients, reduced IL-10 production did not correlate with the presence of the AA genotype in the IL-10 promoter, in keeping with the observation that the defect in IL-10 production is restricted to certain cell groups and it is not universal, as would be expected were it genetically determined.

Importantly, the impairment we observed in IL-10 secretion was not dependent on disease activity, as all patients included were in clinical remission. Therefore, this defect was not a consequence of immune activation but rather, reflected a constitutive deregulation of IL-10 production.

IL-10 can be produced by cells of myeloid and lymphoid origin. Monocytes and macrophages secrete IL-10 in response to bacterial stimuli, which can act upon cells of the innate and acquired immune systems. On the other hand, IL-10 production during $\mathrm{T}$ cell activation can polarize maturing $\mathrm{T}$ cells toward a regulatory IL-10-producing phenotype. Thus, a variety of cell subsets potentially participates in building IL-10 levels in peripheral blood, and the defect observed in Crohn's disease patients could therefore be of diverse cellular origin. With that in mind, we tested the ability of MDDCs and T lymphocytes, as members of the innate and acquired immune systems, respectively, to produce IL-10. Interestingly, the observed phenotype-dependent IL-10 defect appeared to be restricted to the innate immune cellular compartment. IL-10 production by total $\mathrm{CD}_{4}^{+}$lymphocytes from patients with inflammatory, stricturing, or penetrating Crohn's in response to activation was comparable with that observed in inflammatory patients or healthy controls. This suggests that $\mathrm{CD}^{+}$cells do not account for the decrease in IL-10 production observed in the more severe phenotypes of the disease. On the other hand, MDDCs from stricturing patients exhibited a dramatic decrease in IL-10 but not IL-12 production in response to TLR ligation. Consistently, DC-directed differentiation of Thl (IFN- $\gamma$-producing) $\mathrm{CD}_{4}^{+} \mathrm{T}$ cells was not compromised in stricturing patients. Moreover, the patient phenotype did not seem to influence the ability of DCs to drive a Th2, IL-13-producing T cell response. Nonetheless, the possibility exists that the defect in response to stimulation with bacterial components could lead to a defect in induction of IL-10-producing Tregs, which are known to play a role in maintaining mucosal homeostasis.

In summary, our results show a specific impairment in anti-inflammatory cytokine production in severe phenotypes of Crohn's disease, one that is independent from NOD2 and IL-10 promoter polymorphisms as well as from disease activity. These findings are relevant on different levels. First, they provide new insight into the mechanisms potentially underlying the development of complications (i.e., fibrosis and/or fistulae) in Crohn's disease. This may facilitate the development of better strategies for treating this particular group of patients. It may also explain the lack of any therapeutic benefits from rhIL-10 administration in a heterogeneous group of patients. Second, these findings may provide a new predictor of disease evolution by helping to identify those patients with higher risks of developing a more severe phenotype, which accounts for the vast majority of surgical interventions.

\section{ACKNOWLEDGMENTS}

This work was supported by Grant SAF2005-03755 from the Ministerio de Educación y Ciencia, Spain. J. P. has served as a speaker and an advisory board member for Abbott Laboratories, Novartis, Schering-Plough Laboratories, and UCB Pharma. We thank Dr. Miquel Sans, Dr. Elena Ricart, and Dr. Montserrat Aceituno for patient recruitment and Joseph Moore for editorial assistance.

\section{REFERENCES}

1. Louis, E., Collard, A., Oger, A. F., Degroote, E., Aboul Nasr El Yafi, F. A., Belaiche, J. (2001) Behavior of Crohn's disease according to the Vienna classification: changing pattern over the course of the disease. Gut 49, $777-782$.

2. Strober, W., Fuss, I., Mannon, P. (2007) The fundamental basis of inflammatory bowel disease. J. Clin. Invest. 117, 514-521.

3. Medzhitov, R. (2007) Recognition of microorganisms and activation of the immune response. Nature 449, 819-826.

4. Marks, D. J., Harbord, M. W., MacAllister, R., Rahman, F. Z., Young, J. Al-Lazikani, B., Lees, W., Novelli, M., Bloom, S., Segal, A. W. (2006) Defective acute inflammation in Crohn's disease: a clinical investigation. Lancet 367, 668-678.

5. Franchimont, D., Vermeire, S., El Housni, H., Pierik, M., Van Steen, K., Gustot, T., Quertinmont, E., Abramowicz, M., Van Gossum, A., Devière, J., Rutgeerts, P. (2004) Deficient host-bacteria interactions in inflammatory bowel disease? The Toll-like receptor (TLR)-4 Asp299gly polymorphism is associated with Crohn's disease and ulcerative colitis. Gut 53, 987-992.

6. Ahmad, T., Armuzzi, A., Bunce, M., Mulcahy-Hawes, K., Marshall, S. E., Orchard, T. R., Crawshaw, J., Large, O., de Silva, A., Cook, J. T., Barnardo, M., Cullen, S., Welsh, K. I., Jewell, D. P. (2002) The molecular classification of the clinical manifestations of Crohn's disease. Gastroenterology 122, 854-866. 
7. Economou, M., Trikalinos, T. A., Loizou, K. T., Tsianos, E. V., Ioannidis, J. P. (2004) Differential effects of NOD2 variants on Crohn's disease risk and phenotype in diverse populations: a metaanalysis. Am. J. Gastroenterol. 99, 2393-2404.

8. Alvarez-Lobos, M., Arostegui, J. I., Sans, M., Tassies, D., Plaza, S., Delgado, S., Lacy, A. M., Pique, J. M., Yaguie, J., Panés, J. (2005) Crohn's disease patients carrying Nod2/CARD15 gene variants have an increased and early need for first surgery due to stricturing disease and higher rate of surgical recurrence. Ann. Surg. 242, 693-700.

9. Fiorentino, D. F., Bond, M. W., Mosmann, T. R. (1989) Two types of mouse T helper cell. IV. Th2 clones secrete a factor that inhibits cytokine production by Thl clones. J. Exp. Med. 170, 2081-2095.

10. Fedorak, R. N., Gangl, A., Elson, C. O., Rutgeerts, P., Schreiber, S., Wild, G., Hanauer, S. B., Kilian, A., Cohard, M., LeBeaut, A., Feagan, B. (2000) Recombinant human interleukin 10 in the treatment of patients with mild to moderately active Crohn's disease. The Interleukin 10 Inflammatory Bowel Disease Cooperative Study Group. Gastroenterology 119, 14731482.

11. Schreiber, S., Fedorak, R. N., Nielsen, O. H., Wild, G., Williams, C. N., Nikolaus, S., Jacyna, M., Lashner, B. A., Gangl, A., Rutgeerts, P., Isaacs, K., van Deventer, S. J., Koningsberger, J. C., Cohard, M., LeBeaut, A., Hanauer, S. B. (2000) Safety and efficacy of recombinant human interleukin 10 in chronic active Crohn's disease. Crohn's Disease IL-10 Cooperative Study Group. Gastroenterology 119, 1461-1472.

12. Lennard-Jones, J. E. (1989) Classification of inflammatory bowel disease. Scand. J. Gastroenterol. Suppl. 170, 2-6.

13. Satsangi, J., Silverberg, M. S., Vermeire, S., Colombel, J. F. (2006) The Montreal classification of inflammatory bowel disease: controversies, consensus, and implications. Gut 55, 749-753.

14. Romani, N., Reider, D., Heuer, M., Ebner, S., Kämpgen, E., Eibl, B., Niederwieser, D., Schuler, G. (1996) Generation of mature dendritic cells from human blood. An improved method with special regard to clinical applicability. J. Immunol. Methods 196, 137-151.

15. Turner, D. M., Williams, D. M., Sankaran, D., Lazarus, M., Sinnott, P. J., Hutchinson, I. V. (1997) An investigation of polymorphism in the interleukin-10 gene promoter. Eur. J. Immunogenet. 24, 1-8.

16. Tagore, A., Gonsalkorale, W. M., Pravica, V., Hajeer, A. H., McMahon, R., Whorwell, P. J., Sinnott, P. J., Hutchinson, I. V. (1999) Interleukin-10 (IL-10) genotypes in inflammatory bowel disease. Tissue Antigens 54, $386-390$

17. Fichtner-Feigl, S., Fuss, I. J., Young, C. A., Watanabe, T., Geissler, E. K., Schlitt, H. J., Kitani, A., Strober, W. (2007) Induction of IL-13 triggers TGF- $\beta 1$-dependent tissue fibrosis in chronic 2,4,6-trinitrobenzene sulfonic acid colitis. J. Immunol. 178, 5859-5870.

18. Fichtner-Feigl, S., Strober, W., Kawakami, K., Puri, R. K., Kitani, A. (2006) IL-13 signaling through the IL-13 $\alpha 2$ receptor is involved in induction of TGF- $\beta 1$ production and fibrosis. Nat. Med. 12, 99-106.
19. Strobel, S., Mowat, A. M. (1998) Immune responses to dietary antigens: oral tolerance. Immunol. Today 19, 173-181.

20. Roncarolo, M. G., Gregori, S., Battaglia, M., Bacchetta, R., Fleischhauer, K., Levings, M. K. (2006) Interleukin-10-secreting type 1 regulatory T cells in rodents and humans. Immunol. Rev. 212, 28-50.

21. Kuhn, R., Lohler, J., Rennick, D., Rajewsky, K., Muller, W. (1993) Interleukin-10-deficient mice develop chronic enterocolitis. Cell 75, 263-274.

22. Strober, W., Fuss, I. J., Blumberg, R. S. (2002) The immunology of mucosal models of inflammation. Annu. Rev. Immunol. 20, 495-549.

23. Rakoff-Nahoum, S., Hao, L., Medzhitov, R. (2006) Role of Toll-like receptors in spontaneous commensal-dependent colitis. Immunity $\mathbf{2 5}$ $319-329$.

24. Asseman, C., Mauze, S., Leach, M. W., Coffman, R. L., Powrie, F. (1999) An essential role for interleukin 10 in the function of regulatory $\mathrm{T}$ cells that inhibit intestinal inflammation. J. Exp. Med. 190, 995-1004.

25. Meresse, B., Rutgeerts, P., Malchow, H., Dubucquoi, S., Dessaint, J. P., Cohard, M., Colombel, J. F., Desreumaux, P. (2002) Low ileal interleukin 10 concentrations are predictive of endoscopic recurrence in patients with Crohn's disease. Gut 50, 25-28.

26. Colombel, J. F., Rutgeerts, P., Malchow, H., Jacyna, M., Nielsen, O. H., Rask-Madsen, J., Van Deventer, S., Ferguson, A., Desreumaux, P., Forbes, A., Geboes, K., Melani, L., Cohard, M. (2001) Interleukin 10 (Tenovil) in the prevention of postoperative recurrence of Crohn's disease. Gut 49, 42-46.

27. Van Montfrans, C., Rodriguez Pena, M. S., Pronk, I., Ten Kate, F. J., Te Velde, A. A., Van Deventer, S. J. (2002) Prevention of colitis by interleukin 10-transduced T lymphocytes in the SCID mice transfer model. Gastroenterology 123, 1865-1876.

28. Van Montfrans, C., Hooijberg, E., Rodriguez Pena, M. S., De Jong, E. C., Spits, H., Te Velde, A. A., Van Deventer, S. J. (2002) Generation of regulatory gut-homing human $\mathrm{T}$ lymphocytes using ex vivo interleukin 10 gene transfer. Gastroenterology 123, 1877-1888.

29. Steidler, L., Hans, W., Schotte, L., Neirynck, S., Obermeier, F., Falk, W., Fiers, W., Remaut, E. (2000) Treatment of murine colitis by Lactococcus lactis secreting interleukin-10. Science 289, 1352-1355.

30. Gasche, C., Bakos, S., Dejaco, C., Tillinger, W., Zakeri, S., Reinisch, W. (2000) IL-10 secretion and sensitivity in normal human intestine and inflammatory bowel disease. J. Clin. Immunol. 20, 362-370.

31. Hart, A. L., Kamm, M. A., Knight, S. C., Stagg, A. J. (2004) Quantitative and functional characteristics of intestinal-homing memory $\mathrm{T}$ cells: analysis of Crohn's disease patients and healthy controls. Clin. Exp. Immunol. 135, 137-145.

32. Eskdale, J., Gallagher, G., Verweij, C. L., Keijsers, V., Westendorp, R. G., Huizinga, T. W. (1998) Interleukin 10 secretion in relation to human IL-10 locus haplotypes. Proc. Natl. Acad. Sci. USA 95, 9465-9470. 